\title{
Peri-operative Inflammatory Marker as a Predictive Factor for Prolonged Post-operative Ileus After Gastrectomy for Gastric Cancer
}

\author{
Yonsoo Kim, ${ }^{1}$ Young Min Kim, ${ }^{1}$ Jie-Hyun Kim, ${ }^{1}$ Young Hoon Youn, ${ }^{1}$ Jong Won Kim, ${ }^{2}$ and Hyojin Park ${ }^{1 *}$ \\ Departments of ${ }^{1}$ Internal Medicine and ${ }^{2}$ Surgery, Gangnam Severance Hospital, Yonsei University College of Medicine, Seoul, Korea
}

\begin{abstract}
Background/Aims
Although prolonged post-operative ileus (PPOI) is an important factor for the prolonged length of post-operative hospital stay, there is still a lack of effective predictive and therapeutic methods for PPOI. Previous studies reported that increased inflammatory markers, such as C-reactive protein (CRP) level and neutrophil to lymphocyte ratio (NLR), are associated with malignancies. The aim of our study is to elucidate the association between peri-operative inflammatory markers and PPOI after gastrectomy for gastric cancer.
\end{abstract}

\section{Methods}

We enrolled patients who received gastrectomy for gastric cancer from June 2013 to January 2016 at a single tertiary referral center in Seoul, Korea. We evaluated peri-operative inflammatory markers, including CRP level, NLR, and platelet to lymphocyte ratio (PLR) of enrolled patients. We compared these data between control group and PPOI group.

\section{Results}

A total of 390 subjects were enrolled in this study, and 132 patients (33.8\%) showed PPOI. In univariate analysis, preoperative CRP level and NLR, post-operative day (POD) 1 CRP level, NLR, and PLR, and POD3 CRP level, NLR, and PLR were significantly associated with PPOI. In multivariate analysis, preoperative NLR $(P=0.014)$, POD1 NLR $(P=0.019)$, POD3 CRP $(P=0.004)$, and POD3 NLR $(P=$ 0.008) were independent risk factors for PPOI.

\section{Conclusions}

Peri-operative inflammatory markers, such as CRP level and NLR, are useful predictive factors for PPOI who received gastrectomy for gastric cancer. Moreover, prophylactic antibiotics and anti-inflammatory drugs can be preventive and therapeutic agents for PPOI.

(J Neurogastroenterol Motil 2021;27:588-595)

\section{Key Words}

Gastrectomy; Inflammation; Post-operative ileus

Received: September 8, 2020 Revised: January 14, 2021 Accepted: February 7, 2021

(.) This is an Open Access article distributed under the terms of the Creative Commons Attribution Non-Commercial License (http://creativecommons. org/licenses/by-nc/4.0) which permits unrestricted non-commercial use, distribution, and reproduction in any medium, provided the original work is properly cited.

*Correspondence: Hyojin Park, MD, PhD

Department of Internal Medicine, Gangnam Severance Hospital, Yonsei University College of Medicine, 211 Eonjuro, Gangnamgu, Seoul 06273, Korea

Tel: +82-2-2019-3310, Fax: +82-2-3463-3882, E-mail: hjpark21@yuhs.ac

Yonsoo Kim and Young Min Kim contributed equally to this work. 


\section{Introduction}

Post-operative ileus (POI) is known as a temporary impairment of gastrointestinal (GI) motility after surgery. ${ }^{1}$ Patients who have POI present nausea, vomiting, and abdominal discomfort. Symptoms of POI also include a delayed passage of gas and stool or inability to tolerate oral diet. " "Uncomplicated" or "normal" POI is typically identified as an unavoidable process following surgery, which generally resolves within 3 days. "1,2 "Prolonged" or "paralytic" post-operative ileus (PPOI) extends beyond the duration of 3 days. ${ }^{1,2}$ Internationally, there has been a lack of standardized definitions for PPOI, but we believe post-operative day (POD) 4 to be the most acceptable cutoff point as proposed by Vather et $\mathrm{al}^{2}$ based on a systemic review and global study. Additionally, PPOI is an important factor for the prolongation of post-operative hospital stay and excessive hospitalization costs. ${ }^{3}$

Globally, gastric cancer is the third common cause of cancerrelated mortality, and is the most prevalent type of cancer in Eastern Asia, including Japan, Korea, and China. ${ }^{4}$ Enhanced Recovery after Surgery (ERAS) programs were started to improve the postoperative recovery process. ${ }^{5}$ As PPOI is one of the major factors that delays post-operative recovery, ${ }^{3,6}$ preventing POI is a key factor of ERAS. ${ }^{5}$ However, there is still a lack of effective therapeutic and predictive methods for POI. Gastrectomy is inevitably followed by physiologic inflammatory stimuli for surgical stress, which can be observed by elevated white blood cell and C-reactive protein (CRP) levels. ${ }^{7}$ However, cancer patients already have higher levels of preoperative CRP when compared to healthy people or patients with benign disease. ${ }^{8}$ Tumor growth may induce a peritumoral inflammatory growth and therefore, lead to an increase in CRP levels. ${ }^{7,9}$ It has been well known that chronic diseases such as gastric malignancy are associated with a prolonged inflammation which can be confirmed by the increase of other inflammatory parameters. ${ }^{10}$ Some hematological markers, such as neutrophil count, have been identified as both diagnostic and prognostic factors in various malignancies. ${ }^{11}$ The neutrophil to lymphocyte ratio (NLR) has been studied as a simple marker of systemic inflammatory reactions in not only patients with tumors, ${ }^{12,13}$ but also in patients following resection of a range of neoplasms, ${ }^{14}$ including gastric malignancy. ${ }^{15}$ Further, the preoperative platelet to lymphocyte ratio (PLR) has also been proposed as an independent prognostic marker in pancreatic cancer. ${ }^{16}$

Nonetheless, the association between peri-operative inflammatory markers and post-operative complications such as PPOI remains uncertain in gastric cancer surgery. The aim of our study is to investigate the relationship between PPOI and peri-operative inflammatory markers and to explore whether peri-operative NLR, PLR, or CRP levels could be useful independent prognostic indicators for PPOI after gastric cancer surgery.

\section{Materials and Methods}

\section{Patients}

A total of 435 patients who received gastrectomy for gastric cancer from June 2013 to January 2016, at a single tertiary referral center in Seoul, Korea were enrolled. The data from medical records were analyzed retrospectively. All subjects had a preoperative diagnosis of gastric adenocarcinoma on the basis of abdominal CT, esophagogastroduodenoscopy (EGD), and histology of biopsied specimens. The exclusion criteria were as follows: (1) patients who had gastric cancer in the remnant stomach $(\mathrm{n}=10)$; (2) patients who underwent other combined intra-abdominal cancer surgery ( $\mathrm{n}=6)$; (3) unavailability of complete follow-up data $(\mathrm{n}=29)$; and (4) patients who had infection which can affect on the inflammatory markers $(\mathrm{n}=34)$ —surgical wound infection $(\mathrm{n}=20)$, pneumonia $(\mathrm{n}=9)$, colitis $(\mathrm{n}=3)$, and acute pyelonephritis $(\mathrm{n}=$ 2). Based on the above criteria, 390 patients were finally included for analysis. PPOI was defined as ileus persisting for more than 3 days after surgery, and POI less than 3 days was categorized as uncomplicated POI. Enrolled patients were classified into 2 groups, the PPOI group and control (uncomplicated POI) group according to the duration of POI.

The study protocol conformed to the ethical guidelines of the World Medical Association Declaration of Helsinki and was approved by the Institutional Review Board of Gangnam Severance Hospital (IRB No. 3-2019-0265). Informed consent was not required as this study was a retrospective analysis of existing administrative and clinical data.

\section{Data Collection}

The preoperative demographic, clinical, and laboratory blood test data were obtained, including sex, age, body mass index (BMI), comorbidities including diabetes mellitus, objective of surgery (curative or palliative), previous chemotherapy and operation history, preoperative CRP level, neutrophil, lymphocyte, and platelet counts. Surgical factors including the type of surgery (open/converted or laparoscopic operation, total or subtotal gastrectomy, combined or not combined with multiorgan resection); type of recon- 
struction (Billroth I, Billroth II, or Roux-en-Y); and gastric outlet obstruction (partial or complete) were also retrieved. Post-operative outcomes included the day of flatulence. Post-operative laboratory blood test data were collected at POD1 and POD3, because leukocytes increased during POD1 and CRP level peaked at POD3. Resected specimens were examined histopathologically and staged according to the 8th edition of the American Joint Committee on Cancer tumor-node-metastasis (TNM) staging system.

\section{Statistical Methods}

We determined the optimal discriminator value for NLR, PLR, and CRP levels using receiver operating characteristic (ROC) curve analysis. At each value, the sensitivity and specificity for each outcome were plotted, generating a ROC curve. The ratio closest to the point with maximum sensitivity and specificity was selected as the cutoff value and comparisons between groups of patients were performed using the chi-squared test, where appropriate. A $t$ test was used for distributed continuous data. Spearman's rank correlation was used to assess the correlation between ranked data and other factors. To examine the effect of variables on the development of PPOI, we used univariate and multivariate logistic regression analyses. Statistical significance was defined as $P<0.05$. All analyses were conducted using the software program, SPSS ver22.0 (IBM Corp, Armonk, NY, USA).

\section{Results}

Among the 390 subjects who were analyzed, 132 patients who showed a POI for longer than 3 days were categorized as the PPOI group, and the other 258 subjects comprised the control group.

Table 1 shows demographic and clinical characteristics of subjects. The mean age of all the patients was 59.8 years. 311 patients (79.7\%) received laparoscopic gastrectomy, and 78 patients $(20.0 \%)$ received open gastrectomy. For 1 patient, the planned laparoscopic gastrectomy was converted to open gastrectomy in the operating room. Regarding the type of gastrectomy, 191 (49.0\%) and 199 $(51.0 \%)$ patients received total and partial gastrectomy, respectively. In 25 patients, partial or complete gastric outlet obstruction were detected during operation. The Billroth I operation (gastroduodenal anastomosis), Billroth II operation (gastrojejunal anastomosis), and Roux-en-Y gastrojejunostomy were performed in 135 (34.6\%), 43 (11.0\%), and $211(54.1 \%)$ patients respectively.

The association between clinicopathological characteristics and PPOI was analyzed. Table 2 presents the results of the univariate analysis. PPOI was associated with age $\geq 60$ years $(P=0.019)$, male $(P=0.010)$, advanced TNM stage (III and IV, $P=0.004)$, absence of gastric outlet obstruction $(P=0.016)$, open/converted operative technique $(P<0.001)$, and a combination with other or-

Table 1. Demographic and Clinical Characteristics of Subjects

\begin{tabular}{|c|c|}
\hline Characteristics of patients & Overall $(\mathrm{N}=390)$ \\
\hline Age (yr) & $59.8 \pm 12.6$ \\
\hline \multicolumn{2}{|l|}{ Sex } \\
\hline Male & $259(66.4)$ \\
\hline Female & $131(33.6)$ \\
\hline $\mathrm{BMI}\left(\mathrm{kg} / \mathrm{m}^{2}\right)$ & $23.7 \pm 3.4$ \\
\hline \multicolumn{2}{|l|}{ Past history (diabetes) } \\
\hline No & $338(86.7)$ \\
\hline Yes & $52(13.3)$ \\
\hline \multicolumn{2}{|l|}{ Objective of surgery } \\
\hline Curative & $379(97.2)$ \\
\hline Palliative & $11(2.8)$ \\
\hline \multicolumn{2}{|l|}{ TNM stage, AJCC 8th edition } \\
\hline I & $250(64.1)$ \\
\hline II & $55(14.1)$ \\
\hline III & $64(16.4)$ \\
\hline IV & $21(5.4)$ \\
\hline \multicolumn{2}{|l|}{ Gastric outlet obstruction } \\
\hline No & $365(93.6)$ \\
\hline Partial & $22(5.6)$ \\
\hline Complete & $3(0.8)$ \\
\hline \multicolumn{2}{|l|}{ Surgical approach } \\
\hline Laparoscopic & $311(79.7)$ \\
\hline Open & $78(20.0)$ \\
\hline Open conversion & $1(0.3)$ \\
\hline \multicolumn{2}{|l|}{ Type of gastrectomy } \\
\hline Total & $191(49.0)$ \\
\hline Partial & $199(51.0)$ \\
\hline \multicolumn{2}{|l|}{ Operation reconstruction } \\
\hline Billroth I & $135(34.6)$ \\
\hline Billroth II & $43(11.0)$ \\
\hline Roux-en-Y & $211(54.1)$ \\
\hline Double tract & $1(0.3)$ \\
\hline \multicolumn{2}{|l|}{ Adjacent organ resection } \\
\hline No & $324(83.1)$ \\
\hline Colon & $14(3.6)$ \\
\hline Other & $52(13.3)$ \\
\hline \multicolumn{2}{|l|}{ Previous chemotherapy } \\
\hline No & $354(98.5)$ \\
\hline Yes & $6(1.5)$ \\
\hline \multicolumn{2}{|l|}{ Previous operation } \\
\hline No & $356(91.3)$ \\
\hline Yes & $34(8.7)$ \\
\hline
\end{tabular}

BMI, body mass index; TNM, tumor-node-metastasis; AJCC, American Joint Committee on Cancer.

Data are presented as mean $\pm \mathrm{SD}$ or $\mathrm{n}(\%)$. 
Table 2. Relationship Between Clinicopathological Characteristics and Prolonged Post-operative Ileus in Patients Undergoing Gastrectomy: Univariate Analysis

\begin{tabular}{|c|c|c|c|}
\hline Variables & Control $(\mathrm{n}=258)$ & PPOI $(\mathrm{n}=132)$ & $P$-value \\
\hline \multicolumn{4}{|l|}{ Age (yr) } \\
\hline$<60$ & $134(51.9)$ & $52(39.4)$ & \multirow[t]{2}{*}{0.019} \\
\hline$\geq 60$ & $124(48.1)$ & $80(60.6)$ & \\
\hline \multicolumn{4}{|l|}{ Sex } \\
\hline Male & $160(62.0)$ & $99(75.0)$ & \multirow[t]{2}{*}{0.010} \\
\hline Female & $98(38.0)$ & $33(25.0)$ & \\
\hline \multicolumn{4}{|l|}{$\operatorname{BMI}\left(\mathrm{kg} / \mathrm{m}^{2}\right)$} \\
\hline$<25$ & $170(65.9)$ & $74(56.1)$ & \multirow[t]{2}{*}{0.651} \\
\hline$\geq 25$ & $88(34.1)$ & $58(43.9)$ & \\
\hline \multicolumn{4}{|c|}{ Past history (diabetes) } \\
\hline No & $229(88.8)$ & $109(82.6)$ & \multirow[t]{2}{*}{0.089} \\
\hline Yes & $29(11.2)$ & $23(17.4)$ & \\
\hline \multicolumn{4}{|l|}{ Objective of surgery } \\
\hline Curative & $252(97.7)$ & $127(96.2)$ & \multirow[t]{2}{*}{0.409} \\
\hline Palliative & $6(2.3)$ & $5(3.8)$ & \\
\hline \multicolumn{4}{|c|}{ TNM stage, AJCC 8th edition } \\
\hline I/II & $213(82.6)$ & $92(69.7)$ & \multirow[t]{2}{*}{0.004} \\
\hline III/IV & $45(17.4)$ & $40(30.3)$ & \\
\hline \multicolumn{4}{|c|}{ Gastric outlet obstruction } \\
\hline No & $248(96.1)$ & $117(88.6)$ & \multirow[t]{3}{*}{0.016} \\
\hline Partial & $9(3.5)$ & $13(9.8)$ & \\
\hline Complete & $1(0.4)$ & $2(1.5)$ & \\
\hline \multicolumn{4}{|l|}{ Surgical approach } \\
\hline Laparoscopic & $220(85.3)$ & $91(68.9)$ & \multirow[t]{3}{*}{$<0.001$} \\
\hline Open & $37(14.3)$ & $41(31.1)$ & \\
\hline Open conversion & $1(0.4)$ & $0(0.0)$ & \\
\hline \multicolumn{4}{|c|}{ Operation reconstruction } \\
\hline Billroth I & $100(38.8)$ & $35(26.5)$ & \multirow[t]{4}{*}{0.091} \\
\hline Billroth II & $26(10.1)$ & $17(12.9)$ & \\
\hline Roux-en-Y & $131(50.8)$ & $80(60.6)$ & \\
\hline Double tract & $1(0.4)$ & $0(0.0)$ & \\
\hline \multicolumn{4}{|c|}{ Combined organ resection } \\
\hline No & $217(84.1)$ & $107(81.1)$ & \multirow[t]{3}{*}{0.047} \\
\hline Colon & $5(1.9)$ & $9(6.8)$ & \\
\hline Others & $36(14.0)$ & $16(12.1)$ & \\
\hline \multicolumn{4}{|c|}{ Previous chemotherapy } \\
\hline No & $256(99.2)$ & $128(97.0)$ & \multirow[t]{2}{*}{0.087} \\
\hline Yes & $2(0.8)$ & $4(3.0)$ & \\
\hline \multicolumn{4}{|l|}{ Previous operation } \\
\hline No & 237 (91.9) & $119(90.2)$ & \multirow[t]{2}{*}{0.571} \\
\hline Yes & $21(8.1)$ & $13(9.8)$ & \\
\hline
\end{tabular}

BMI, body mass index; TNM, tumor-node-metastasis; AJCC, American Joint Committee on Cancer. Data are presented as $\mathrm{n}(\%)$.

gan resection $(P=0.047)$. The other factors were not significantly associated with PPOI, including BMI, past history of diabetes, objective of surgery, types of reconstruction, previous chemotherapy, and previous operation history.

Peri-operative laboratory values were compared between the PPOI and control groups. Comparison of peri-operative laboratory 
data, including CRP level, NLR, and PLR, between the PPOI and control groups is summarized in Table 3. Peri-operative inflammatory markers showing significant differences were CRP level and NLR during preoperative period; NLR at POD1; and CRP level,

Table 3. Peri-operative Laboratory Data Between the Groups

\begin{tabular}{lccr}
\hline \multicolumn{1}{c}{ Variables } & $\begin{array}{c}\text { Control } \\
(\mathrm{n}=258)\end{array}$ & $\begin{array}{c}\text { PPOI } \\
(\mathrm{n}=132)\end{array}$ & P-value \\
\hline Preoperative marker & & & \\
CRP $(\mathrm{mg} / \mathrm{L})$ & $2.55 \pm 0.39$ & $5.25 \pm 13.76$ & 0.034 \\
NLR & $2.02 \pm 1.19$ & $2.28 \pm 1.27$ & 0.041 \\
PLR & $134.34 \pm 56.14$ & $146.00 \pm 73.49$ & 0.087 \\
POD1 marker & & & \\
CRP (mg/L) & $46.19 \pm 27.50$ & $51.31 \pm 28.09$ & 0.085 \\
NLR & $6.74 \pm 4.01$ & $7.79 \pm 4.79$ & 0.023 \\
PLR & $172.59 \pm 96.68$ & $194.37 \pm 128.82$ & 0.063 \\
POD3 marker & & & \\
CRP (mg/L) & $103.31 \pm 58.77$ & $137.32 \pm 69.84$ & $<0.001$ \\
NLR & $5.33 \pm 3.02$ & $6.76 \pm 3.81$ & 0.040 \\
PLR & $172.42 \pm 81.81$ & $191.97 \pm 100.97$ & $<0.001$ \\
\hline
\end{tabular}

PPOI, prolonged post-operative ileus; CRP, C-reactive protein; NLR, neutrophil to lymphocyte ratio; PLR, platelet to lymphocyte ratio; POD, postoperative day.

Data are presented as mean $\pm \mathrm{SD}$.
NLR, and PLR at POD3, all of which were significantly higher in the PPOI group in contrast to the control group. However, there were no statistically significant differences in the preoperative PLR, POD1 CRP level, and POD1 PLR.

We performed ROC curve analysis for pre and post-operative laboratory blood test data. For all 390 gastric cancer patients, the value with the highest sensitivity and specificity was selected. The preoperative CRP level, NLR, and PLR were $1.35 \mathrm{mg} / \mathrm{L}, 2.18$, and 167.12, respectively. The POD1 CRP level, NLR, and PLR were $51.5 \mathrm{mg} / \mathrm{L}, 7.72$, and 234.03, respectively. The POD3 CRP level, NLR, and PLR were $107.15 \mathrm{mg} / \mathrm{L}, 5.51$, and 167.49 , respectively. The cutoff values of each inflammatory marker with their corresponding sensitivity and specificity are shown in Supplementary Table 1 .

In univariate analysis, age $\geq 60$ years, male sex, gastric outlet obstruction, adjacent colon resection, open surgery, advanced TNM stage (III and IV), preoperative CRP level $\geq 1.35 \mathrm{mg} /$ $\mathrm{L}$, preoperative NLR $\geq 2.18$, POD1 CRP level $\geq 51.5 \mathrm{mg} /$ L, POD1 NLR $\geq 7.72$, POD1 PLR $\geq 234.03$, POD3 CRP level $\geq 107.15 \mathrm{mg} / \mathrm{L}$, POD3 NLR $\geq 5.51$, and POD3 PLR $\geq$ 167.47 had significant association with PPOI (Table 4). The multivariate logistic regression analysis, conducted using the clinico-

Table 4. Clinicopathologic Characteristics and Prolonged Post-operative Ileus in Patients Undergoing Gastrectomy: Univariate and Multivariate Logistic Regression Analysis

\begin{tabular}{|c|c|c|c|c|}
\hline \multirow{2}{*}{ Variables } & \multicolumn{2}{|c|}{ Univariate analysis } & \multicolumn{2}{|c|}{ Multivariate analysis } \\
\hline & $\chi^{2}$ & $P$-value & OR $(95 \% \mathrm{Cl})$ & $P$-value \\
\hline Age $\geq 60 \mathrm{yr}$ & 5.508 & 0.019 & $1.527(0.970-2.405)$ & 0.067 \\
\hline Male & 6.600 & 0.010 & $0.635(0.388-1.039)$ & 0.071 \\
\hline Gastric outlet obstruction & 8.228 & 0.016 & $1.598(0.130-19.655)$ & 0.405 \\
\hline Adjacent colon resection & 6.111 & 0.047 & $1.679(0.480-5.878)$ & 0.490 \\
\hline Open surgery & 15.638 & $<0.001$ & $2.664(1.561-4.547)$ & 0.002 \\
\hline TNM stage (III/IV), AJCC 8th edition & 8.474 & 0.004 & $1.225(0.673-2.229)$ & 0.506 \\
\hline \multicolumn{5}{|l|}{ Preoperative marker } \\
\hline $\mathrm{CRP} \geq 1.35(\mathrm{mg} / \mathrm{L})$ & 4.169 & 0.041 & $1.307(0.823-2.075)$ & 0.256 \\
\hline $\mathrm{NLR} \geq 2.18$ & 7.224 & 0.007 & $1.607(1.006-2.565)$ & 0.047 \\
\hline PLR $\geq 167.12$ & 3.569 & 0.059 & $1.464(0.865-2.479)$ & 0.156 \\
\hline \multicolumn{5}{|l|}{ POD1 marker } \\
\hline $\mathrm{CRP} \geq 51.5(\mathrm{mg} / \mathrm{L})$ & 4.545 & 0.033 & $1.357(0.857-2.148)$ & 0.193 \\
\hline $\mathrm{NLR} \geq 7.72$ & 7.643 & 0.006 & $1.778(1.101-2.871)$ & 0.019 \\
\hline PLR $\geq 234.03$ & 5.667 & 0.017 & $1.634(0.921-2.899)$ & 0.093 \\
\hline \multicolumn{5}{|l|}{ POD3 marker } \\
\hline $\mathrm{CRP} \geq 107.15(\mathrm{mg} / \mathrm{L})$ & 15.933 & $<0.001$ & $1.987(1.239-3.188)$ & 0.004 \\
\hline $\mathrm{NLR} \geq 5.51$ & 15.405 & $<0.001$ & $1.879(1.177-2.998)$ & 0.008 \\
\hline PLR $\geq 167.49$ & 6.079 & 0.014 & $1.552(0.988-2.437)$ & 0.057 \\
\hline
\end{tabular}

PPOI, prolonged post-operative ileus; TNM, tumor-node-metastasis; AJCC, American Joint Committee on Cancer; CRP, C-reactive protein; NLR, neutrophil to lymphocyte ratio; PLR, platelet to lymphocyte ratio; POD, post-operative day. 
laboratory factors determined in the univariate analysis, identified that open surgery $(\mathrm{OR}, 2.664 ; 95 \% \mathrm{CI}, 1.561-4.547 ; P=0.002)$, preoperative $\mathrm{NLR} \geq 2.18(\mathrm{OR}, 1.607 ; 95 \% \mathrm{CI}, 1.006-2.565 ; P$ $=0.047)$, POD1 NLR $\geq 7.72(\mathrm{OR}, 1.778 ; 95 \% \mathrm{CI}, 1.101-2.871$; $P=0.019)$, POD3 CRP $\geq 107.15 \mathrm{mg} / \mathrm{L}(\mathrm{OR}, 1.987 ; 95 \% \mathrm{CI}$, 1.239-3.188; $P=0.004)$, and POD3 NLR $\geq 5.51$ (OR, 1.879; 95\% CI, 1.177-2.998; $P=0.008$ ) were independent risk factors for PPOI in patients with gastric cancer.

We performed additional analysis in patients undergoing open gastrectomy and laparoscopic gastrectomy, respectively. In the univariate analysis for open gastrectomy, preoperative $\mathrm{NLR} \geq 2.18$, POD1 NLR $\geq 7.72$, and POD3 NLR $\geq 5.51$ had significant association with PPOI (Supplementary Table 2). In the multivariate analysis, preoperative NLR $\geq 2.18$ (OR, 3.741; 95\% CI, 1.32710.547; $P=0.013)$, POD1 NLR $\geq 7.72$ (OR, 4.069; 95\% CI, 1.452-11.401; $P=0.008$ ) were independent risk factors for PPOI in patients who underwent open surgery.

In laparoscopic gastrectomy, age $\geq 60$ years, male sex, gastric outlet obstruction, adjacent colon resection, advanced TNM stage (III and IV), preoperative CRP level $\geq 1.35 \mathrm{mg} / \mathrm{L}$, POD3 CRP level $\geq 107.15 \mathrm{mg} / \mathrm{L}$, POD3 NLR $\geq 5.51$, and POD3 PLR $\geq 167.47$ had significant association with PPOI (Supplementary Table 3 ). In the multivariate analysis, age $\geq 60$ years $(\mathrm{OR}, 1.728$; 95\% CI, 1.020-2.927; $P=0.024)$, adjacent colon resection (OR, 6.073; 95\% CI, 1.145-32.225; $P=0.034)$, POD3 CRP level $\geq 107.15 \mathrm{mg} / \mathrm{L}(\mathrm{OR}, 2.258 ; 95 \% \mathrm{CI}, 1.344-3.794 ; P=0.002)$, POD3 NLR $\geq 5.51$ (OR, 1.861; 95\% CI, 1.112-3.114; $P=$ 0.018 ) were independent risk factors for PPOI in patients who underwent laparoscopic surgery.

\section{Discussion}

This study showed that peri-operative inflammatory markers had independent association with the development of PPOI. Several previous studies reported that there is a correlation between systemic inflammation and complication after cancer surgery. ${ }^{15}$ However, this study is the first to report the relationship between the incidence of post-operative PPOI and inflammatory markers in gastric cancer surgery.

CRP level, NLR, and PLR are simple, readily measurable laboratory markers. However, the optimal cutoff values for CRP level, NLR, and PLR to predict PPOI remains unclear. Varying normal levels of CRP are defined by institutes $(<6 \mathrm{mg} / \mathrm{L}$ in our center), but there is no determined cutoff value for NLR and PLR. A cutoff value of 5 for NLR is often chosen on the basis of previous studies and used in clinical practice although different values have been used in studies on colorectal cancer. ${ }^{17}$ In another study, the cutoff value of NLR was 2.5 for bladder cancer, ${ }^{18}$ and $4.0,{ }^{13} 2.57,{ }^{19}$ and $1.44^{20}$ for gastric cancer. The cutoff value or PLR is $160^{19}$ and $180^{20}$ for gastric cancer. In our study, we identified the optimal cutoff for CRP level, NLR, and PLR using ROC curve analysis.

An elevation in CRP level is considered to be associated with the immune system and poor survival. ${ }^{21}$ Further, the elevation in NLR and PLR has recently been identified as a strong prognostic marker for multiple malignancies, including colorectal cancer, ${ }^{22}$ pancreatic ductal adenocarcinoma, ${ }^{23}$ and others. ${ }^{12,24-27}$

The relationship between elevated inflammatory markers and infectious complications after operation remains unclear; however, NLR may provide a possible explanation. An increase in the number of neutrophils is induced by bacterial contamination of the operation site. ${ }^{28}$ A high NLR reflects both strengthened neutrophilinduced inflammatory response and weakened lymphocyte-mediated antibacterial response, which has been believed to affect various cancer patients, including those with gastric cancer. ${ }^{29-31}$ Stimulated immature neutrophils which tend to release superoxide anions in response to surgical stress, may influence oxygen radical-mediated tissue injury and bacterial invasion of the surgical site. ${ }^{31}$

Although the precise mechanism remains unclear, the results of this study suggest that NLR as a simple inflammatory biomarker, may identify patients at increased risk for post-operative complications after gastrectomy for gastric cancer. Many studies have been conducted to identify whether NLR is superior to PLR. According to these studies, neutrophilia in contrast to thrombocytosis is a more sensitive reaction and could represent the inflammatory activity of the tumor. ${ }^{27,28}$ Cancer-related inflammation, characterized by an elevation of NLR, induces decrease of antitumor immunity via the accumulation of regulatory $\mathrm{T}$ cells and elevated secretion of chemokines resulting in tumor growth and metastasis. Therefore, inflammation may result in aggressive growth of the tumor. Alternatively host cell immunity could be deteriorated by the cancer, thereby affecting the host's outcomes such as post-operative complications. ${ }^{28}$

Various factors involved in POI act by reducing the contractility of the muscularis externa (ME) and delaying the GI transit time. These typical factors include anesthetics, post-operative drugs, and inflammatory mediators secreted by immune cells. ${ }^{32,33}$ In normal conditions, ME macrophages respond to luminal bacterial infection and interact with enteric neurons to regulate GI motility. ${ }^{34}$ When macrophages are stimulated by luminal bacterial infections, leukocytes, especially monocytes and neutrophils, are attracted to the ME. When surgical stimulus is added, ME macrophages are 
activated, leading to a decrease in muscle contraction and a delay in intestinal transit. ${ }^{35}$ In rodents, inactivation of macrophage before surgery inhibited the activity of leukocytes and improved GI transit. $^{36}$ In addition, anti-inflammatory mediators such as interleukin (IL)-10 and polyunsaturated fatty acids-derived pro-resolving molecules are involved in the recovery of intestinal motility. ${ }^{37-40}$ Based on previous studies that confirm their relation to inflammation and POI, peri-operative inflammatory markers can be used as a tool for predicting PPOI.

Among peri-operative inflammatory markers, preoperative NLR and POD1 NLR were independent risk factors for PPOI in open surgery. In the case of laparoscopic surgery, POD3 CRP levels and POD3 NLR were independent risk factors for PPOI. This result may be associated with difference of surgical range between open and laparoscopic gastrectomy. Since surgical range and stress of open surgery is more extensive and stronger than laparoscopic surgery, neutrophil-induced inflammatory response may be activated earlier in the patients after open surgery than laparoscopic surgery.

Our study has several limitations. First, this study is limited by its retrospective design. Second, the use of medication for pain control was not considered, especially exogenous opioids, which may contribute to impaired GI motility and affect POI. Third, patients who underwent previous treatments, such as endoscopic mucosal resection or endoscopic submucosal dissection, were included. These interventions can alter preoperative inflammatory markers.

In conclusion, although preoperative tumor staging is valuable for selecting the appropriate therapeutic strategy for patients with gastric cancer, clinical tumor staging alone cannot predict postoperative complication and prognosis. ${ }^{41}$ Our study suggests that the peri-operative systemic inflammatory markers, which is easily measurable, may be clinically useful to identify patients at increased risk for PPOI and predict longer post-operative hospitalization.

The inflammatory markers should be routinely monitored in order to identify an abnormal response, complications, and infection in advance.

The administration of therapeutic agents such as prokinetics or prophylactic antibiotics, should be considered targeting the varied aspects of the systemic inflammatory response. Further study on medications for the modulation of systemic inflammation to improve peri-operative outcomes after resection for cancer will be needed.

\section{Supplementary Materials}

Note: To access the supplementary tables mentioned in this article, visit the online version of Journal of Neurogastroenterology and Motility at http://www.jnmjournal.org/, and at https://doi. org/10.5056/jnm20203.

\section{Financial support: None.}

\section{Conflicts of interest: None.}

Author contributions: Yonsoo Kim and Young Min Kim substantial contributions to conception and design, or acquisition, analysis and interpretation of data, drafting the article, or revising it critically for important intellectual content; Hyojin Park substantial contributions to conception and design, final approval of the version to be published, and agreement to be accountable for all aspects of the work; and Jie-Hyun Kim, Young Hoon Youn, and Jong Won Kim revising the article critically for important intellectual content. All authors reviewed the manuscript.

\section{References}

1. Artinyan A, Nunoo-Mensah JW, Balasubramaniam S, et al. Prolonged postoperative ileus-definition, risk factors, and predictors after surgery. World J Surg 2008;32:1495-1500.

2. Vather R, Trivedi S, Bissett I. Defining postoperative ileus: results of a systematic review and global survey. J Gastrointest Surg 2013;17:962972.

3. Iyer S, Saunders WB, Stemkowski S. Economic burden of postoperative ileus associated with colectomy in the United States. J Manag Care Pharm 2009;15:485-494.

4. Torre LA, Bray F, Siegel RL, Ferlay J, Lortet-Tieulent J, Jemal A. Global cancer statistics, 2012. CA Cancer J Clin 2015;65:87-108.

5. Mortensen K, Nilsson M, Slim K, et al. Consensus guidelines for enhanced recovery after gastrectomy: enhanced recovery after surgery (ERAS®) society recommendations. Br J Surg 2014;101:1209-1229.

6. Kehlet H. Fast-track colorectal surgery. Lancet 2008;371:791-793.

7. Csendes JA, Muñoz ChA, Burgos L. Blood count and C-reactive protein evolution in gastric cancer patients with total gastrectomy surgery. Arq Bras Cir Dig 2014;27:234-236.

8. Heikkila K, Ebrahim S, Lawlor DA. A systematic review of the association between circulating concentrations of $\mathrm{C}$ reactive protein and cancer. $\mathrm{J}$ Epidemiol Community Health 2007;61:824-833.

9. Kim DK, Oh SY, Kwon HC, et al. Clinical significances of preoperative serum interleukin-6 and C-reactive protein level in operable gastric cancer. BMC Cancer 2009;9:155.

10. Ohzato H, Yoshizaki K, Nishimoto N, et al. Interleukin-6 as a new indicator of inflammatory status: detection of serum levels of interleukin-6 
and C-reactive protein after surgery. Surgery 1992;111:201-209.

11. Shimada H, Oohira G, Okazumi S, et al. Thrombocytosis associated with poor prognosis in patients with esophageal carcinoma. J Am Coll Surg 2004;198:737-741.

12. An X, Ding PR, Li YH, et al. Elevated neutrophil to lymphocyte ratio predicts survival in advanced pancreatic cancer. Biomarkers 2010;15:516522.

13. Shimada H, Takiguchi N, Kainuma O, et al. High preoperative neutrophil-lymphocyte ratio predicts poor survival in patients with gastric cancer. Gastric Cancer 2010;13:170-176.

14. Tsujimoto H, Ichikura T, Ono S, et al. Impact of postoperative infection on long-term survival after potentially curative resection for gastric cancer. Ann Surg Oncol 2009;16:311-318.

15. Templeton AJ, McNamara MG, Šeruga B, et al. Prognostic role of neutrophil-to-lymphocyte ratio in solid tumors: a systematic review and meta-analysis. J Natl Cancer Inst 2014;106:dju124.

16. Bhatti I, Peacock O, Lloyd G, Larvin M, Hall RI. Preoperative hematologic markers as independent predictors of prognosis in resected pancreatic ductal adenocarcinoma: neutrophil-lymphocyte versus plateletlymphocyte ratio. Am J Surg 2010;200:197-203.

17. Walsh SR, Cook EJ, Goulder F, Justin TA, Keeling NJ. Neutrophillymphocyte ratio as a prognostic factor in colorectal cancer. J Surg Oncol 2005;91:181-184.

18. Kaynar M, Yıldırım ME, Badem H, et al. Bladder cancer invasion predictability based on preoperative neutrophil-lymphocyte ratio. Tumor Biol 2014;35:6601-6605.

19. Aliustaoglu M, Bilici A, Ustaalioglu BB, et al. The effect of peripheral blood values on prognosis of patients with locally advanced gastric cancer before treatment. Med Oncol 2010;27:1060-1065.

20. Jiang N, Deng JY, Liu Y, Ke B, Liu HG, Liang H. The role of preoperative neutrophil-lymphocyte and platelet-lymphocyte ratio in patients after radical resection for gastric cancer. Biomarkers 2014;19:444-451.

21. McMillan DC, Wotherspoon HA, Fearon KC, Sturgeon C, Cooke TG, McArdle CS. A prospective study of tumor recurrence and the acutephase response after apparently curative colorectal cancer surgery. Am J Surg 1995;170:319-322.

22. Kwon HC, Kim SH, Oh SY, et al. Clinical significance of preoperative neutrophil-lymphocyte versus platelet-lymphocyte ratio in patients with operable colorectal cancer. Biomarkers 2012;17:216-222.

23. Domínguez I, Fernández-del Castillo C. Preoperative platelet-lymphocyte ratio in resected pancreatic ductal carcinoma: is it meaningful? Am J Surg 2012;203:412.

24. Mohri Y, Tanaka K, Toiyama Y, et al. Impact of preoperative neutrophil to lymphocyte ratio and postoperative infectious complications on survival after curative gastrectomy for gastric cancer: a single institutional cohort study. Medicine 2016;95:e3125.

25. Shamamian P, Schwartz JD, Pocock BJ, et al. Activation of progelatinase A (MMP-2) by neutrophil elastase, cathepsin $\mathrm{G}$, and proteinase-3: a role for inflammatory cells in tumor invasion and angiogenesis. J Cell Physiol
2001;189:197-206.

26. Cihan YB, Ozturk A, Mutlu H. Relationship between prognosis and neutrophil: lymphocyte and platelet: lymphocyte ratios in patients with malignant pleural mesotheliomas. Asian Pac J Cancer Prev 2014;15:2061-2067.

27. Petrie HT, Klassen LW, Kay HD. Inhibition of human cytotoxic T lymphocyte activity in vitro by autologous peripheral blood granulocytes. J Immunol 1985;134:230-234.

28. Shau HY, Kim A. Suppression of lymphokine-activated killer induction by neutrophils. J Immunol 1988;141:4395-4402.

29. Kabir S, Daar GA. Serum levels of interleukin-1, interleukin-6 and tumour necrosis factor-alpha in patients with gastric carcinoma. Cancer Lett 1995;95:207-212.

30. Ikuta S, Miki C, Tanaka K, et al. Serum immunosuppressive acidic protein as an interleukin-6 related index of deteriorating condition in gastric cancer patients. Dig Surg 2003;20:532-538.

31. Djeu JY, Serbousek D, Blanchard DK. Release of tumor necrosis factor by human polymorphonuclear leukocytes. Blood 1990;76:1405-1409.

32. Boeckxstaens GE, de Jonge WJ. Neuroimmune mechanisms in postoperative ileus. Gut 2009;58:1300-1311.

33. Farro G, Stakenborg M, Gomez-Pinilla PJ, et al. CCR2-dependent monocyte-derived macrophages resolve inflammation and restore gut motility in postoperative ileus. Gut 2017;66:2098-2109.

34. Muller PA, Koscsó B, Rajani GM, et al. Crosstalk between muscularis macrophages and enteric neurons regulates gastrointestinal motility. Cell 2014;158:200-313.

35. de Jonge WJ, van den Wijngaard RM, The FO, et al. Postoperative ileus is maintained by intestinal immune infiltrates that activate inhibitory neural pathways in mice. Gastroenterology 2003;125:1137-1147.

36. Wehner S, Behrendt FF, Lyutenski BN, et al. Inhibition of macrophage function prevents intestinal inflammation and postoperative ileus in rodents. Gut 2007;56:176-185.

37. Stoffels B, Schmidt J, Nakao A, Nazir A, Chanthaphavong RS, Bauer AJ. Role of interleukin 10 in murine postoperative ileus. Gut 2009;58:648-660.

38. Wehner S, Meder K, Vilz TO, et al. Preoperative short-term parenteral administration of polyunsaturated fatty acids ameliorates intestinal inflammation and postoperative ileus in rodents. Langenbecks Arch Surg 2012;397:307-315.

39. Stein K, Stoffels M, Lysson M, et al. A role for 12/15-lipoxygenasederived proresolving mediators in postoperative ileus: protectin DXregulated neutrophil extravasation. J Leukoc Biol 2016;99:231-239.

40. van Bree SH, Nemethova A, van Bovenkamp FS, et al. Novel method for studying postoperative ileus in mice. Int J Physiol Pathophysiol Pharmacol 2012;4:219-227.

41. Nakajima K, Ochiai T, Suzuki T, et al. Impact of preoperative serum carcinoembryonic antigen, CA 19-9 and alpha fetoprotein levels in gastric cancer patients. Tumor Biol 1998;19:464-469. 